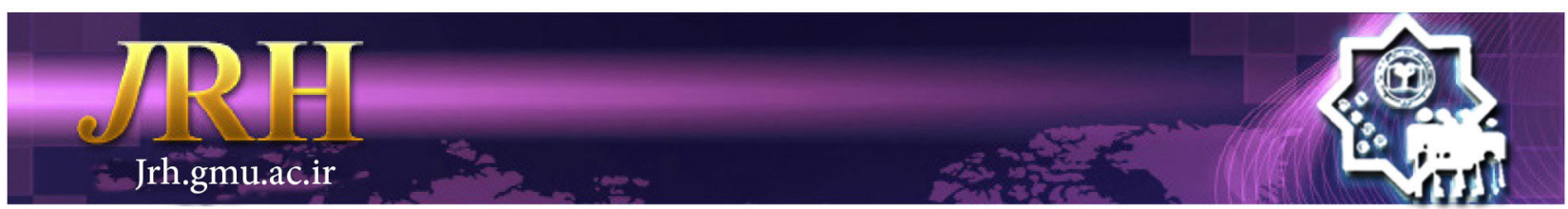

\title{
Predicting the intention to perform physical activity in the elderly based on the theory of planned behavior
}

Mohammad Vahedian-Shahroodi ${ }^{1}$, Mahdi Moshki², Habibollah Esmaily ${ }^{3}$, Somaye Moradi Gholezo ${ }^{4}$, Elaheh Lael- Monfared ${ }^{5}$, Maryam Damirchi ${ }^{6}$

Journal of Research \& Health

Social Development \& Health Promotion Research Center

Vol. 9, No.4, Jul \& Agu 2019

Pages: $324-329$

DOI: 10.29252/jrh.9.4.324

Original Article

1. Department of Health Education and Health Promotion, School of Health, Mashhad University of Medical Science, Mashhad, Iran 2. Department of Health Education and Health Promotion, School of Health; Social Development and Health Promotion Research Center, Gonabad University of Medical Sciences, Gonabad, Iran

3. Department of Statistics, School of Health, Mashhad University of Medical Science, Mashhad, Iran

4. Correspondence to: Department of Health Education, School of Health, Mashhad University of Medical Science, Mashhad, Iran Email: moradis1@mums.ac.ir

5. Department of Public Health, Student Research Committee, School of Public Health and Safety, Shahid Beheshti University of Medical Sciences, Tehran, Iran

6. Department of Health Education, school of Health, Baqiyatallah University of Medical Sciences, Tehran, Iran

Received: 4 Apr 2015

Accepted: 23 May 2017

How to cite this article:Vahedian-Shahroodi M, Moshki M, Esmaily H, Moradi Gholezo S, Lael-Monfared E, Damirchi M. Predicting the intention to perform physical activity in the elderly based on the theory of planned behavior in the city of Kalat. $J$ Research \& Health2019; 9(4): 324- 329 .

\section{Introduction}

The world Health Organization (WHO) acknowledges the rate of physical activity and mobility in the society as the first health criterion [1]. Physical activity is a behavior effective in preventing various diseases, promoting a healthy lifestyle, and decreasing mortality due to different reasons. Regular activity as

\begin{abstract}
Today, with increasing the lifespan, the importance of healthpromoting behavior and paying attention to maintaining individuals' function and autonomy are becoming increasingly evident and regular physical activity is considered as one of the important aspects of healthy lifestyle. This study aimed to apply the theory of planned behavior to predict the intention to do physical activity in the elderly. This study was conducted on the 371 elderly. A three-part questionnaire including demographic, knowledge, and theory of planned behavior questions was used. The views of the elderly were requested directly in this regard. According to the results, the elderly's mean age was 69 and the sample included $53 \%$ women. The behavior intention in this study had a positive significant correlation with all planned behavior theory constructs. The perceived behavior control construct hold the most prediction power regarding the variance of the elderly's intention of physical activity behavior. The constructs of theory could predict $26.7 \%$ of the variance of intention. Based on the results of this study, the theory of planned behavior was successful in predicting the elderly's intention to do physical activity and the necessity of paying attention to the component is emphasized to teach intention to elderly people, considering the role of the perceived behavior control construct in predicting behavior intention.
\end{abstract}

Keywords: Elderly, Physical Activity, theory of planned behavior an important factor in a healthy lifestyle plays a vital role in decreasing mortality due to diseases. According to the WHO report, annually 1.9 million deaths are due to physical immobility around the world. Therefore, it is listed as one of the 15 priorities of changing behavior to improve the health. It is estimated 
that immobility is the cause of $10-16 \%$ of the diseases such as diabetes and breast, colon, and rectum cancer, and about $22 \%$ of the heart ischemic diseases [2]. The studies show that a low level of activity is transformed from youth to adolescence and remains stable [3]. Today, there are over 600 million elderly people which will be doubled by 2025 and reach 2 billion by 2050 from 841 million in 2013 [4]. In Italy, only $3.5 \%$ of the elderly have regular activity and $2.2 \%$ state that they do not perform regular activity [5]. In the United States of America (USA), $60 \%$ of the adolescents do not take part in a regular activity plan and $31 \%$ of them never take part in these plans. This issue is different in the elderly so that $66 \%$ of the elderly over 75 -years-old take part in no regular activity. In addition, $50 \%$ of the inactive elderly have no plan to start an activity. According to the Iran ministry of health, treatment, and medical education, over 6.2 of the Iranian population are 65-years-old currently. The studies show that over $80 \%$ of the population is physically inactive [6]. The results of a study on over 55-year-old people in Iran showed that no one of the people did sufficiently (20 minutes activity for at least 3 times a week or more) moderate activity, in Tehran also $80 \%$ of men and $85 \%$ of women do no activity even as walking outside the work or home environment [6].

In the last decades, researchers have used several theoretical models to predict and figure out the behavior of physical activity where the Theory of Planned Behavior (TBP) has taken much attention and its prediction has been shown to be valid in different populations of adolescents $[7,8]$. According to the TBP, people assess a behavior positively and do it if they believe that important persons think that the behavior is to be done and also doing that behavior is under their control. In this theory, it is assumed that attitude, subjective, and control norms are determined by the underlying ideas of these constructs. The theory constructs often predict $40-50 \%$ of the variance of activity in different meta-analyses [9].

Considering the growing proportion of this part of the population in all countries and the heavy burden of immobile lifestyle on the public health system, there is a need for the development of interventions to promote an active lifestyle. Therefore, the identification of cognitive-social factors of persons' intention to perform a physical activity is an appropriate approach [8]. This can be helpful in educational planning to encourage people to have more physical activity and effective interactions. Therefore, the present study utilized the TBP to investigate the factors related to the intention to perform regular physical activity among the elderly.

\section{Method}

This study was planned in a cross-sectional way to assess the status of activity in the elderly of Kalat city, one of the towns in the North East of Razavi Khorasan province in Iran, in 2014 using the planned behavior theory. After providing identification to do a research work, a sample of 371 participants was assessed and selected through a purposeful sampling. Inclusion criteria included being old (over 60 -years-old), willing to participate in the research, and lacking physical inability. The data collection tool was a questionnaire with three parts. The first part was researcher-made and included demographic questions to gather information such as age, height, and weight of the old person, sexuality, education level, marital status, job, and average income. The other part was designed to measure knowledge with 10 questions, attitude with 11 questions, subjective norms with 3 questions, perceived behavior control with 6 questions, and behavior intention with 3 questions that were used in creating the part of the questionnaire related to the knowledge and variables of TBP $[2,9]$. In order to measure physical activity, the International physical activity questionnaire was used. Accordingly, the physical activity behavior of individuals was classified as low mobility and sufficient mobility [10]. In order to increase the accuracy and clarity [10], as well as the face and content validity of the questions, the questionnaire was reevaluated. Content validity for the constructs 
of knowledge was $88 \%$, attitude $91 \%$, intention $84 \%$, subjective norms $95 \%$, and perceived behavior control $92 \%$. The content validity ratio for the constructs of knowledge was $85 \%$, attitude $94 \%$, intention $100 \%$, subjective norms $91 \%$, and perceived behavior control $95 \%$. The Cronbach's alpha of the total questionnaire was $82.8 \%$ for reliability measurement.

The knowledge consisted of 10 questions answered as yes, no, and I do not know, so that yes scored 1 while no and I do not know scored zero. The attitude included 11 questions scored on a five-point Likert scale, with a score of 1 to 5 in a way that completely disagree scored 1 and completely agree scored 5 . The subjective norms consisted of 3 questions and perceived behavior control included 6 questions, on a five-point Likert scale of completely disagree to completely agree. The behavioral intention included 3 questions on a five-point Likert scale from very likely to very unlikely scoring from 1 to 5. Considering that multiplication and division have no effect on the results of statistical tests, the questionnaire scores were computed based on 100 to simplify comparing all the scores of different parts of the questionnaire.

The questionnaires were distributed to the sample and the aims were declared to the target group to complete the questionnaires for 15 minutes as self-reporting. If someone were illiterate, the questionnaire would be completed through an interview. After completing all questionnaires, data were entered into the statistical software and analyzed. Data analysis was done using SPSS16 by descriptive tests (interquartile mean, range, frequency, and percentage) and analytical tests (correlation coefficient, chi-square, and linear regression) at a significance level of 0.05 . Is should be noted that participants' satisfaction was taken before beginning the research and all ethical principles were considered in all of the steps. All steps were done by obtaining a permit from the relevant authorities (Governorate of Kalat, and health and treatment network management).

\section{Results}

The mean age of the participants was 69 and a mean body mass index was 23.4. In view of demographic variables, $53 \%$ were women, $72.2 \%$ were married, $69.7 \%$ were illiterate, and $1.4 \%$ had a diploma or higher degree. $40 \%$ of them were living with their spouse and children. In view of physical activity, $56.2 \%$ of the elderly were with low activity and $43.8 \%$ with sufficient activity. The results showed that the level of physical activity was significantly related to marital status, living condition, and education level of the old person but not to body mass index (Table 1).

\begin{tabular}{|c|c|c|c|c|c|c|c|}
\hline & & \multicolumn{2}{|c|}{ Low mobility } & \multicolumn{2}{|c|}{ Sufficient mobility } & \multirow{2}{*}{ Test statistic } & \multirow{2}{*}{ p-value } \\
\hline & & Percentage & Number & Percentage & Number & & \\
\hline \multirow{2}{*}{ Material status } & Married & 140 & 4.52 & 127 & 6.47 & \multirow{2}{*}{$\mathrm{x}^{2}=5.57$} & \multirow{2}{*}{0.018} \\
\hline & Single & 68 & 0.66 & 35 & 0.34 & & \\
\hline \multirow{2}{*}{ Literacy condition } & Literate & 50 & 6.44 & 62 & 4.55 & \multirow{2}{*}{$x^{2}=8.74$} & \multirow{2}{*}{0.003} \\
\hline & Illiterate & 158 & 2.61 & 100 & 8.38 & & \\
\hline \multirow{3}{*}{ Living condition } & Whit spouse & 74 & 2.61 & 47 & 8.38 & \multirow{3}{*}{$x^{2}=19.77$} & \multirow{3}{*}{0.001} \\
\hline & Couple and father & 79 & 1.45 & 96 & 9.54 & & \\
\hline & Single & 55 & 3.74 & 19 & 7.25 & & \\
\hline \multirow{4}{*}{ Body mass index } & Less than 22 & 71 & 7.59 & 48 & 3.40 & \multirow{4}{*}{$x^{2}=1.60$} & \multirow{4}{*}{0.659} \\
\hline & $22-24.9$ & 70 & 4.57 & 52 & 6.42 & & \\
\hline & $25-29.9$ & 52 & 0.52 & 48 & 0.48 & & \\
\hline & More than 30 & 15 & 7.51 & 14 & 3.48 & & \\
\hline
\end{tabular}

The mean score of knowledge was 80 , attitude 81 , subjective norms and perceived behavior control 60, and intention 40 (Table 2). The multiple regression test showed that the planned behavior theory constructs predicted $26 \%$ of the variance of physical activity behavior intention in the model (Table 3). 
Predicting the intention to perform physical activity

Table 2 Scores' interquartile mean and range of knowledge and constructs of TBP among the participants

\begin{tabular}{lcccc}
\hline & Middle & Medieval range & Minimum & Maximum \\
\hline Knowledge & 8 & 4 & 0 & 10 \\
Attitude & 45 & 13 & 16 & 55 \\
Subjective norm & 9 & 4 & 3 & 15 \\
Perceived behavior control & 18 & 6 & 6 & 30 \\
Behavioral intention & 6 & 5 & 3 & 15 \\
\hline
\end{tabular}

Table 3 Multiple regression analysis to determine the relationship between the constructs of the TBP and the intention of physical activity behavior among the participants

\begin{tabular}{lccccc}
\hline Independent variables & Standardized beta & $\mathrm{T}$ & $\mathrm{p}$-value & $\mathrm{R}^{2}$ & $\begin{array}{c}\text { Dependent } \\
\text { variables }\end{array}$ \\
\hline Attitude & 0.186 & 4.12 & 0.007 & & \\
Subjective norm & 0.138 & 2.48 & 0.013 & 0.267 & Behavior intention \\
Perceived behavior control & 0.386 & 7.00 & 0.001 & & \\
\hline
\end{tabular}

Correlation test results showed a significant relationship between intention to do physical activity and attitude ( $\mathrm{p}=0.003, \mathrm{r}=0.152)$, perceived behavior control $(\mathrm{r}=0.417$, $\mathrm{p}<0.001)$, and subjective norms $(\mathrm{p}<0.001$, $\mathrm{r}=0.340)$ (Table 4).

Table 4 Spearman correlation coefficient matrix between the constructs of TBP and the variables of knowledge among the participants

\begin{tabular}{lcccccc}
\hline & Knowledge & Attitude & $\begin{array}{c}\text { Perceived } \\
\text { behavior control }\end{array}$ & $\begin{array}{c}\text { Subjective } \\
\text { norm }\end{array}$ & Intention & $\begin{array}{c}\text { Physical activity } \\
\text { behavior }\end{array}$ \\
\cline { 2 - 7 } & $\mathrm{r}$ & $\mathrm{r}$ & $\mathrm{P}$ & $\mathrm{r}$ & $\mathrm{r}$ & $\mathrm{r}$ \\
& $\mathrm{P}$ & $\mathrm{P}$ & $\mathrm{P}$ & $\mathrm{P}$ & $\mathrm{P}$ & $\mathrm{P}$ \\
\hline Knowledge & 1 & 0.644 & 0.052 & 0.216 & 0.140 & 0.148 \\
& & 0.001 & 0.319 & 0.001 & 0.007 & 0.004 \\
Attitude & 0.644 & & -0.016 & 0.086 & 0.152 & 0.184 \\
& 0.001 & 1 & 0.001 & 0.99 & 0.003 & 0.001 \\
Perceived behavior control & 0.052 & -0.016 & & 0.552 & 0.417 & 0.145 \\
& 0.319 & 0.001 & 1 & 0.001 & 0.001 & 0.005 \\
Subjective norm & 0.216 & 0.086 & 0.552 & & 0.344 & 0.149 \\
& 0.001 & 0.99 & 0.001 & 1 & 0.001 & 0.004 \\
Intention & 0.140 & 0.152 & 0.417 & 0.344 & & 0.260 \\
Physical activity behavior & 0.007 & 0.003 & 0.001 & 0.001 & & 0.001 \\
& 0.148 & 0.184 & 0.145 & 0.149 & 0.260 & 1 \\
\hline
\end{tabular}

\section{Discussion}

In this study on the elderly's views about physical activity, we observed that the majority of them were in a relatively proper status in terms of knowledge and attitude but they were in a moderate status in terms of other constructs. There was a significant relationship between all the constructs and behavioral intention. In the study of Huger et al. in 2002, there was a real and strong connection between each one of the constructs and physical activity [11]. In this study, the construct of perceived behavior control had the greatest effect on the intention and attitude and abstract norms constructs were in the next ranks, respectively. In the study of Gonsun et al., aiming at comparing activity in two groups of the general population and pregnant women, the perceived behavior control had the greatest correlation with intention [12]. In the study of Mazloomi et al, to predict the use of helmet using this theory, the effect of perceived behavior control on the intention prediction was more than the 
effect of the other constructs [13], which is consistent with our study results. In the study of Rhodes on examining the factors predicting students' exercise intention, the attitude had the highest correlation with intention and perceived behavior control had the least correlation [14]. In the study of de Bruijin, which was done to determine the use of bicycle using this theory, the attitude had the highest correlation with the intention to use bicycles, followed by the perceived behavior control and abstract norms [15]. In the studies of Gahremani et al. [2], Huger et al. [14], and Jackson et al. [16], contrary to our study, perceived behavior control construct did not have a significant role in predicting physical activity intention in the elderly. Thus, the effect of perceived behavior control depends on the existence or absence of simplifiers or obstacles to do a behavior or perceived power. This result shows that the society feels that there is no control for doing activity due to the existence of some obstacles. The research has shown that one of the determinants of doing activity is obstacles a person is dealing with to do this behavior. In contrast, the abilities to overcome barriers to physical activity have a positive significant relationship with increased physical activity. Physical activity has also a direct connection with having a suitable place for exercise and equipment and providing a vehicle for going to the exercise place. Individuals are tempted to perform healthy behaviors (such as physical activity), and even do it in dealing with challenges if they feel that they are controlling the behavior. It is also necessary for training plans to reinforce this idea in the elderly that they can have regular and sufficient activity despite the obstacles. Using motivating interviews and holding meetings can be helpful to increase self-efficiency in the elderly.

People can promote their life quality and health by assigning a little time to physical activity in daily life. Mobility and regular activity at old ages can decrease pain and disability caused by diseases such as arthritis, osteoporosis, and high blood pressure [17].

Although the results of this study increased our insight into factors explaining physical activity behavior based on the proposed theory, it still had some limitations. First, a cross-sectional study was used in this design to declare the relationships between variables. The basic feature of cross-sectional studies is that data are collected in a period and this can limit the ability to determine causality relations between the variables. Second, since data are collected as self-report, they may not reflect the real function of individuals. Similar to any other human research that uses a questionnaire, there was the possibility of incorrect responses although we tried to clearly express the research aims and observe ethical principles in the research and more importantly, achieve a high sample size to minimize the effect of this limitation on the results validity.

\section{Conclusion}

Totally, the study revealed the relative importance and relations of proposed model constructs with the intention. Thus, it is needed to pay attention to these relationships while designing training interventions to promote activity intention in the elderly. The health observers should work on perceived behavior control, subjective norms, and attitude that are effective on the behavior in order to increase motivation or intention of doing an activity or decrease immobile lifestyle in the elderly. Regarding the results of the study that perceived behavior control was the strongest construct in predicting activity intention, it seems increasing knowledge and providing training are not enough to promote the culture of exercise and activity among the elderly of Kalat city but the authorities must try to decrease and eliminate obstacles and limitations and do more follow-ups. Nevertheless, since a few studies have been done in the country on the intention and studies done based on this model on the other behaviors, especially on physical activity and exercise, have shown different results, other studies are recommended in the field.

\section{Acknowledgments}

In the end, we appreciate the honorable 
Governor and the manager of the Health and Treatment Center of Kalat due to the coordination with us and also all the dear elderly who helped us with this research.

\section{Authors' contributions}

Study design: MVSh, MM, SMGh

Data collection and analysis: SM, HE, ELM, SMGh

Manyscript preparation: SMGh, EM, MM

All authors have read and approved the final version.

\section{Conflict of Interest}

"The authors declare that they have no competing interests".

\section{Funding}

The author (s) received no financial support for the research, authorship and/or publication of this article.

\section{Availability of data and materials}

The datasets used and/or analyzed during this study are available from the corresponding author on reasonable request.

\section{References}

1- Nejati V, Kordi R, Shoaei F. Paper: factors influencing physical activity in the elderly, district 17 of Tehran. Journal of Ageing2010; 4(14): 52.

2- Saber F, Shhnazi H, Sharifirad GH. Check the ingredients of the theory of planned behavior in physical activity students Nain of Payam Noor University of 2013.Health Systems Research2013; 9(9):10-20.

3- Ziadi Lotf Abaddi M, Vafa F, Tavakkoli Rad M, et al. Elderly \& health. Mashhad: Hamsaiee Aftab; 2013.

4- Lucioni DC, Donner C, De Benedetto F, et al. I costi della broncopneumopatia cronica ostruttiva: la fase prospettica dello studio ICE (Italian Costs for Exacerbations in COPD). Pharmacoeconomics Italian Research Articles2005; 7(2): 119-34.

5- Ghahremani L, Nazari M. Comparing prediction power of exercise intention and behavior based on selfefficacy and theory of planned behavior. Payesh2013; 12(1): 99-107.

6- Colcombe SJ, Erickson KI, Raz N, et al. Aerobic fitness reduces brain tissue loss in aging humans. $J$ Gerontol A Biol Sci Med Sci2003; 58(2): 176-80.

7- Pate RR, Pratt M, Blair SN, et al. Physical activity and public health: a recommendation from the centers for disease control and prevention and the American college of sports medicine. JAMA1995; 1;273(5):4027.

8- Blue CL. The predictive capacity of the theory of reasoned action and the theory of planned behavior in exercise research: An integrated literature review. Res Nurs Health1995; 18(2): 105-21.

9- Motl RW, Dishman RK, Saunders RP, et al. Examining social-cognitive determinants of intention and physical activity among black and white adolescent girls using structural equation modeling. Health Psychol2002; 21(5): 459-67-

10- Vahedian-Shahroodi M, Lael-Monfared E, Esmaily H, Tehrani H, Hamidreza MH. Prediction of osteoporosis preventive behaviors using the health belief model. Iranina Journal of Health Education and Health Promotion2014; 2(3): 199-207.

11- Hagger MS, Chatzisarantis NL, Biddle SJ. A metaanalytic review of the theories of reasoned action and planned behavior in physical activity: Predictive validity and the contribution of additional variables. $J$ Sport Exerc Psychol2002; 24(1): 3-32.

12- Godin G, Valois P, Lepage L. The pattern of influence of perceived behavioral control upon exercising behavior: An application of Ajzen's theory of planned behavior. J Behav Med1993;16(1):81-102.

13- Mazloomy Mahmood Abad S, Mehri A, Morovati Sharif Abad M, Fallahzadeh H. Application of extended model of planned behavior in predicting helmet wearing among motorcyclist clerks in Yazd. Journal of Birjand University of Medical Sciences2008; 14(4): 9-15.

14- Rhodes RE, Courneya KS. Threshold assessment of attitude, subjective norm, and perceived behavioral control for predicting exercise intention and behavior. Psychol Sport Exerc2005; 6(3): 349-61.

15- de Bruijn G-J, Kremers SP, Schaalma H, Van Mechelen W, Brug J. Determinants of adolescent bicycle use for transportation and snacking behavior. Prev Med2005; 40(6): 658-67.

16- Jackson C, Smith A, Conner M. Applying an extended version of the theory of planned behaviour to physical activity. J Sports Sci2003; 21(2): 119-33.

17- Marcus BH, Pinto BM, Simkin LR, Audrain JE, Taylor ER. Application of theoretical models to exercise behavior among employed women. Am J Health Promot 1994; 9(1): 49-55.

\footnotetext{
Copyright $(\mathcal{C} 2016$ ASP Ins. This open-access article is published under the terms of the Creative Commons Attribution-NonCommercial 4.0 International License which permits Share (copy and redistribute the material in any medium or format) and Adapt (remix, transform, and build upon the material) under the Attribution-NonCommercial terms.
} 